\title{
Qualitative and Quantitative Analysis of University Students' Ability to Relate Calculus Knowledge to Function Graphs
}

\section{Dr. Emre Tokgoz, Quinnipiac University}

Emre Tokgoz is currently the Director and an Assistant Professor of Industrial Engineering at Quinnipiac University. He completed a Ph.D. in Mathematics and another Ph.D. in Industrial and Systems Engineering at the University of Oklahoma. His pedagogical research interest includes technology and calculus education of STEM majors. He worked on several IRB approved pedagogical studies to observe undergraduate and graduate mathematics and engineering students' calculus and technology knowledge since 2011. His other research interests include nonlinear optimization, financial engineering, facility allocation problem, vehicle routing problem, solar energy systems, machine learning, system design, network analysis, inventory systems, and Riemannian geometry.

\section{Hasan Alp Tekalp}

Mrs. elif naz tekalp

My name is Elif Naz Tekalp. I am a junior industrial engineering student at Quinnipiac University. I also have mathematics and general business minor. I am interested in the role of mathematics in engineering education and professional life. I was very passionate about the research that I participated with my Dr. Emre Tokgoz.

\section{Berrak Seren Tekalp BST, Quinnipiac University}

My name is Berrak Seren Tekalp, I am from Turkey, and I am a junior in Industrial Engineering at Quinnipiac University. I have a mathematics and a general business minor. Beginning in my sophomore year, I've done many academic types of research with my professors. In these projects, I have used advanced features within the IBM SPSS Statistics and Excel programs. I am a hard and reliable worker. I have been able to expand my communication skills, and through my time as an active member of multiple student organizations and engineering groups at Quinnipiac. I've led numerous meetings and club projects. I am comfortable with working in teams. 


\title{
Qualitative and Quantitative Analysis of University Students' Ability to Relate Calculus Knowledge to Function Graphs
}

\author{
${ }^{1}$ Emre Tokgöz, ${ }^{1}$ Berrak S. Tekalp, ${ }^{1}$ Elif. N. Tekalp, and ${ }^{2}$ Hasan A. Tekalp \\ ${ }^{1}$ Emre.Tokgoz@qu.edu, ${ }^{1}$ Elif.Tekalp@qu.edu, ${ }^{1}$ Berrak.Tekalp@qu.edu, ${ }^{2}$ Hasan.Tekalp@qu.edu \\ ${ }^{1}$ Industrial Engineering, School of Engineering, Quinnipiac University, Hamden, CT, 06518 \\ ${ }^{2}$ Mechanical Engineering, School of Engineering, Quinnipiac University, Hamden, CT, 06518
}

In this work, 19 undergraduate engineering students' responses to a set of power series questions are collected at a university located on the Northeast region of the United States. Qualitative (video recorded oral interview) and quantitative (written) responses of the participants are analyzed. Understanding learners' ability to construct and reconstruct certain mental structures and organizing them in schemas to solve mathematical problems are the main goals of the analysis. The results of this work can help mathematics and engineering educators to develop a successful teaching methodology after weaknesses of the students are investigated. A new analysis methodology called Triangulation of the data is also introduced in this work. The collected data is analyzed by using both Action-Process-Object-Schema (APOS) and the Triangulation methodologies. The analysis of the research question indicated most of the participants Action classification. The Triangulation methodology can also be used by educators for evaluation of learners.

\section{Introduction}

It is the nature of engineering and mathematics educators to find out about engineering students' success in answering calculus questions, particularly the questions that involve more than one calculus concept that requires to know other calculus concepts. Efforts have been made in understanding engineering students' ability to respond calculus questions in Science-Technology-Engineering-Mathematics (STEM) fields that require knowledge of more than one calculus concept [9] and more research results are added every year to these results for understanding students' approach to solve these problems. New teaching methods are designed to serve STEM students better by using these results. Empirical data collected on university students' answers to conceptual calculus questions is the key to measure their success in answering conceptual calculus questions with multiple underlying calculus concepts. For instance, understanding the calculus aspect of a function's graph in two-dimensional space would require the knowledge of first and second derivatives, limit calculations, horizontal and vertical asymptotes, and the ability to connect all these concepts to be able to provide a correct answer to the question.

We used Action-Process-Object-Schema (APOS) theory to analyze 19 undergraduate engineering students' ability to respond to a calculus question that has multiple parts requiring the conceptual knowledge of first and second derivatives, limit calculations, horizontal and vertical asymptotes. The research methodology explained in this work received IRB approval at a university located on the Northeast region of the United States. The participants were undergraduate engineering students majoring in three different engineering disciplines: Civil, Industrial, and Mechanical. The collected quantitative data consisted of numerical responses of the research participants to parts (a) - (h) of the question related to a variety of different calculus concepts. APOS theory is applied to mathematical topics (mostly functions) by Asiala, Brown, DeVries, Dubinsky, Mathews, and Thomas in 1997 [1], and they explained this theory as the combined knowledge of a student in a specific subject based 
on Piaget's philosophy from 1970s [7]. The collected qualitative data consisted of the transcription of the participants' video recorded interviews; the purpose of the follow-up interviews was to explore the depth of students' conceptual knowledge on the research subject. The quantitative analysis of the question consisted of probabilistic results of the correct responses attained for parts (a) - (h) of the question. Overall, qualitative and quantitative analysis of the data indicated strong horizontal and vertical asymptote knowledge of participants while the main weakness appeared to be determining the domain of the function when the first derivative of the function is positive and negative.

\section{Action-Process-Object-Schema (APOS) Theory}

Breidenbach, Dubinsky, Hawks and Nichols studied students' conceptual view of the function in 1992 ([3]) that relied on Piaget's study of functions in 1977 ([8]) in mathematics education used for forming action-processobject idea ([8]). APOS theory is applied in 1997 ([1]) to mathematical topics (mostly functions); the theory is explained to be the combined knowledge of a student in a specific subject. It is used for observing conceptual construction of students on sub-concepts and schemas; researchers used this theory to observe mathematics learners' ability to build on their existing knowledgebase. APOS theory was not always appropriate for data analysis of pedagogical research ([4]). Cooley, Trigueros and Baker reported results in 2007 ([5]) using thematization of schema with the intent to expose those possible structures acquired at the most sophisticated stages of schema development. Responses of research participants to a calculus graphing problem was analyzed in [2] by using APOS theory. The components of the APOS theory can be briefly explained as follows ([6]):

- An action is a transformation of objects perceived by the as essentially external and as requiring, either individual explicitly or from memory, step-by-step instructions on how to perform the operation...

- The individual reflects upon an action when the action is repeated and he or she can make an internal mental construction called a process by which the individual can think of as performing the same kind of action without an external support...

- An object is results from individual's awareness of the process' totality and realizes that transformations can act on it...

- A schema is a linkage of collected actions, processes, objects, and other schemas that help to form a framework by using general principles in individual's mind...

The nature of this research was appropriate to apply APOS theory because of the nature of the data and the involvement of mathematical concepts such as limits, derivatives, and asymptotes. Participants in this research were expected to look at a given graph and be able to respond to a set of questions step-by-step. For a detailed review of the APOS theory see [6].

The next section contains the details of the research methodology used for collecting the data, APOS classification of the research participants, the triangulation methodology applied to analyze the data, and examples of research participants' written responses used for APOS classification.

\section{Nature of the Collected Data \& Analysis of the Data}

The empirical data displayed in the next section is collected during the 2018-19 academic year at a Northeastern mid-sized institution. Institutional Review Board (IRB) approval is attained for the conducted data collection procedure. The research participants were 19 engineering students and the participation requirement was completion of the second course of a three-course calculus sequence that totals to 12 credits. A research questionnaire was given to students to collect written responses initially. A video recorded follow- 
up oral interview was conducted for asking participants additional questions on their written responses for a better understanding of their conceptual understanding. A questionnaire consisting of several calculus questions was given to the participating students by three members of the research team. Pre- and postinterview responses of the participants to the research question displayed in Figure 1 are evaluated in this work.

By using the graph

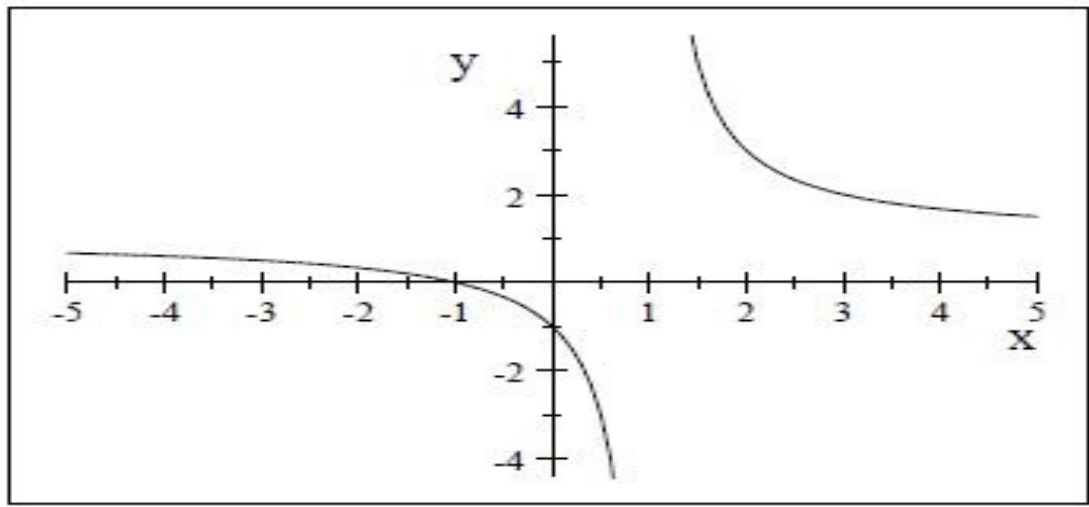

please answer the following questions. If the question does not have an answer please put an $X$ in the box.
a. $\lim _{x \rightarrow-\infty} f(x)=\ldots$ and $\lim _{x \rightarrow \infty} f(x)=$
b. Vertical asymptotes when $x=$
c. Horizontal asymptote when $y=$
d. If $x=c$ is a vertical asymptote then $\lim _{x \rightarrow c^{+}} f(x)=\longrightarrow \lim _{x \rightarrow c^{-}} f(x)=-$
e. $f^{\prime \prime}(x)<0$ when $x<\longrightarrow$,
f. $f^{\prime \prime}(x)>0$ when $x>$
g. Is there any $x=c$ such that $f^{\prime \prime}(c)=0$ for $-1<c<1$ Yes No
h. $f^{\prime}(x)<0$ when $x \in$ and $f^{\prime}(x)>0$ when $x \in$

Figure 1. IRB approved research question analyzed in this work for empirical data analysis.

Examples of both the pre- and post-interview results along with the qualitative and quantitative analysis of the collected data are displayed in this section. The quantitative data analysis consisted of the statistical results in addition to the Triangulation and APOS classification while the qualitative data analysis was based on the responses of the participants. The analysis method displayed in this work can particularly help educators to design a structured method of grading while it can also help with viewing their students' standpoint on understanding the concepts.

APOS theory, as explained previously, can help following learners' abilities in responding mathematics applications and how much they are capable of conceptualizing what they have learned; however, it doesn't necessarily help with quantification of their knowledge from a measurable perspective. In this work we introduce a new method called Triangulation that is used for measuring participants' correct responses depending on the difficulty level of the question. This method can be used by pedagogical researchers and educators to quantitatively measure learners' understanding based on correct responses to a variety of questions that are related to each other based on the difficulty level of the questions.

\subsection{Triangulation of Participants' Responses}

In this section we introduce the Triangulation methodology and how it is used for analysis of the empirical data. The fill-in-the-blank nature of the research question helped to summarize the research participants' responses to all questions on a single spreadsheet as displayed in Figure 2 below. The responses in this figure are designed in 
such a way that the evaluator of the questionnaire can analyze the data easily and apply a method by which the most challenging question for the students is placed to the far right of the triangle and the easiest question is placed on the far left. The top row contains the question numbers while the column displays the research participants' assigned research IDs. The highlighted areas in this figure display the correct responses of the participants. The RP order is listed from the most successful to the least successful for the most part; however, as expected, the correct responses of the participants are not uniformly distributed therefore the large triangle in this figure does not cover all the correct responses of the participants. The "/" sign is used between "preinterview" and "post-interview responses. The answers are highlighted if the post-interview responses are correct due to research participants' ability to derive the correct answer eventually.

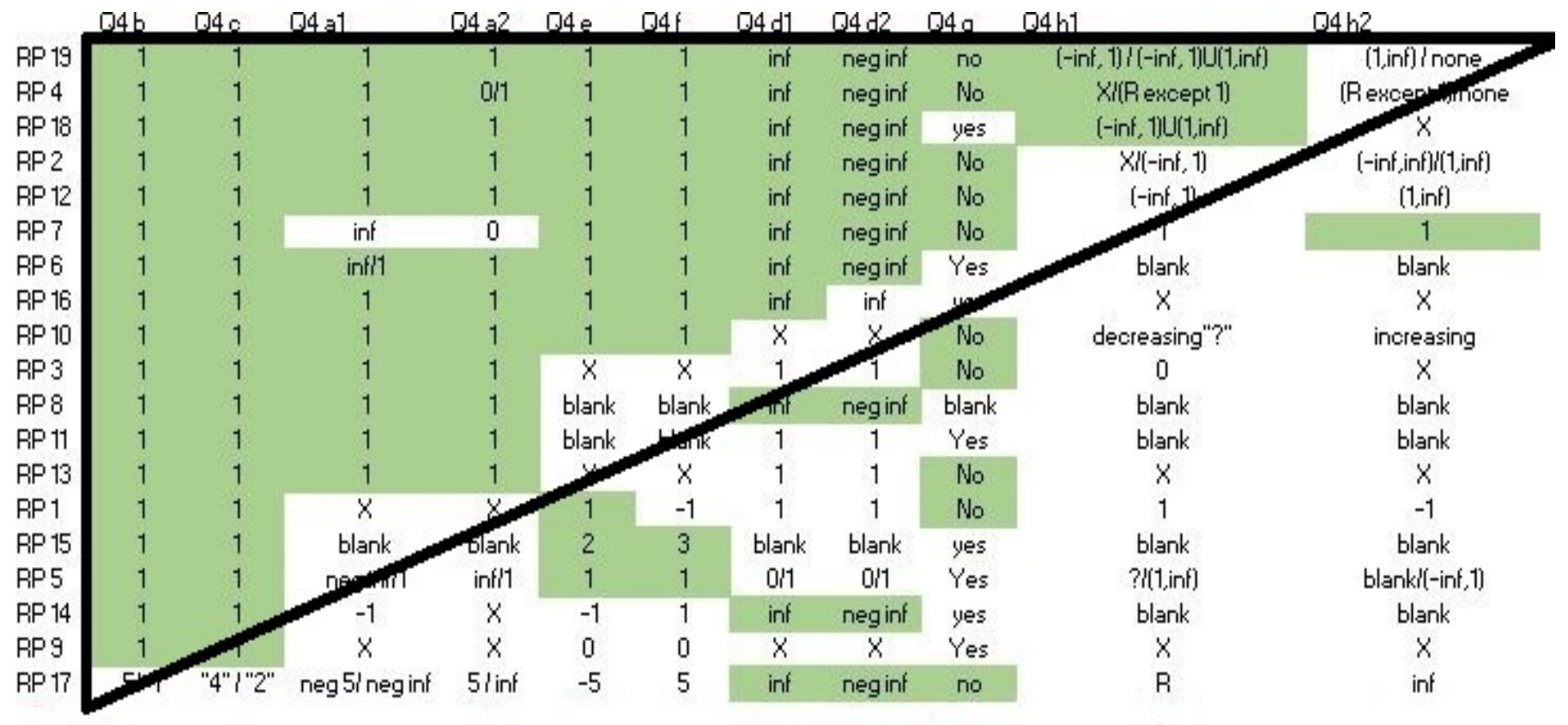

Figure 2. All responses of the research participants to the research question with highlighted correct responses and triangulation of the correct responses.

The triangle in Figure 2 contains a triangular coverage of most of the correct responses of the participants. There is a total of 209 responses displayed on Figure 2. 86.32\% of the correct responses (101/117) fall within the large triangle displayed on the figure; even though the triangle does not contain all the highlighted correct responses, it is a strong indicator of the success of the students in a specific order. For instance, parts Q4-a2 and Q4-e of the question have the same number of responses however the "triangulation" of the data yielded to the specific question and participant order in the figure. The order of the questions in the spreadsheet can be organized in such a way that the questions are ordered from the least to most important question or vice versa, or without any order of the questions to form a triangulation of the responses. Part Q4-g might seem to be outof-place (or outlier) in the triangle however an adjustment can be made on the triangle to incorporate the responses if the evaluator decides to place more value on this part.

The responses displayed in Figure 2 indicate the highest success level of participants 4, 18 and 19 while the second success group consisted of participants 2, 6, 7, and 12. The Triangulation of the correct responses also helped to observe an outstanding participant RP 7 whose responses to all the questions didn't match with other responses; RP 7 was the only person who answered Q4-h2 correct however the participant's response to Q4-h1 was incorrect which lowered this participant's classification within the group of participants. Mismatching 
correctness of the responses to Q4-h1 and Q4-h2 indicated incomplete conceptual understanding of the participant 7 that lowered the classification of the participant within the research participant group. The third group members consisted of participants 3, 8, 10, 13 and 16. The fourth group consisted of participants 1, 5, 11, 14 and 15 . The fifth group is formed by participants 9 and 17. These success groups are designed as a result of the number of correct responses within the corresponding challenge level of the question from left to the right. The ordering of the question can be instructor dependent and therefore the above-mentioned classification can change at instructor's will. Table 1 below summarizes the correct response triangulation of the participants.

\begin{tabular}{l|l|l}
\hline Group Classification & Participant (RP) & Percentage (\%) \\
\hline Fifth & 9,17 & 10.52 \\
\hline Fourth & $1,5,11,14,15$ & 26.32 \\
\hline Third & $3,8,10,13,16$ & 26.32 \\
\hline Second & $2,6,7,12$ & 21.05 \\
\hline First & $4,18,19$ & 15.79 \\
\hline
\end{tabular}

Table 1. Classification of the participants based on the triangulation of correct responses

\subsection{APOS Classification \& Triangular Evaluation of the Research Participants}

In this section we analyze the Action-Process-Object-Schema classification of the research participants. The following APOS descriptions that were introduced previously in the introduction will be used to classify the research data.

- Action: The participants were able to transform the given information to the graph by performing the required operations to achieve the expected solution for limits, derivative or asymptote to an extent. The participants in this group respond to the research questions during the pre- or post-interview period based on each sub-calculus concept.

- Process: The individual reflects upon the action when the action is repeated and he or she can make an internal mental construction called a process by which the individual can think of as performing the same kind of action without an external support. The participants classified in this group were able to answer the research question without any guidance from the researcher per sub-calculus concept covered in the question. For instance, part (e) of the question was the first question related to the second derivative of the function while part (f) is the second part of the derivative question at which the participant can make it a process to answer part (f) correct regardless of receiving help or not (from the interviewer) to answer part (e) correct.

- Object: The individual is aware of the connectedness of the calculus sub-concepts that take place in the question (i.e. derivative, limit and asymptote) and uses this totality by transforming it to answer the questions correctly...

- Schema: The participant links actions, processes, objects, and other schemas that help to form a framework by using general principles in mind. In other words, the participant can make informed judgement of each step of the calculus sub-concepts that take place on the graph and connects these sub-concepts to be able to answer the question correct. For instance, the participant should be able to tell that a concave down function with decreasing nature would have a negative second derivative value with a negative first derivative value; this would be the combination of answering parts (e) and (h) of the question correctly and the participant should realize that there is a connection between the responses to these two parts. 
Table 2 outlines the APOS classification of the participants based on the outlined APOS descriptions above.

\begin{tabular}{l|l|l}
\hline \multicolumn{1}{c|}{ Classification } & Participant (RP) & Percentage (\%) \\
\hline Action & $1,5,7,9,11,14-18$ & 52.63 \\
\hline Process & $3,10,13$ & 15.79 \\
\hline Object & $2,6,12$ & 15.79 \\
\hline Schema & $4,18,19$ & 15.79 \\
\hline
\end{tabular}

Table 2. APOS classification of the research participants

The rest of this section is devoted to the responses of some of the participants to the research question. For instance, Participant 1 with the written work displayed below had hard time to make a connection between the parts of the question to have a comprehensive response to all parts of the question. The response of this participant contained conceptual conflicts for attaining a comprehensive solution for the entirety of the question.

4. By using the graph

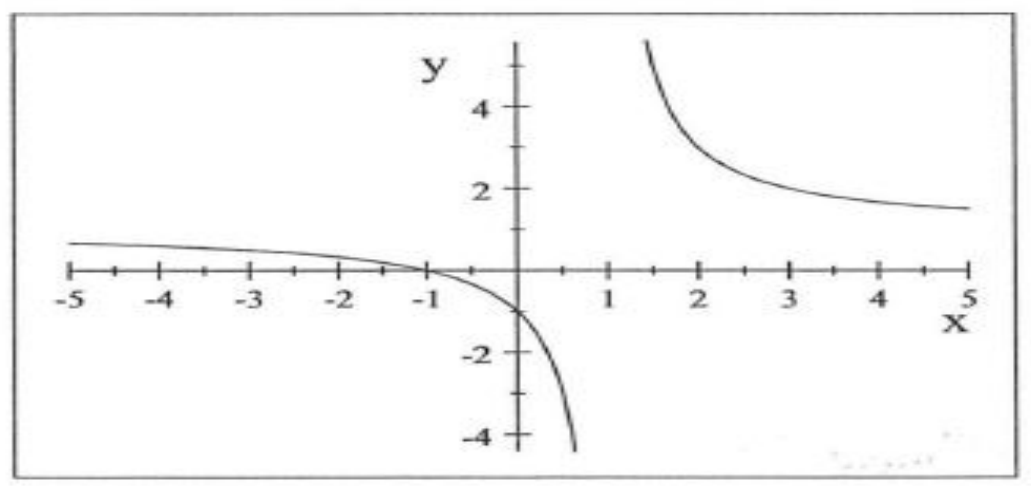

please answer the following questions. If the question does not have an answer please put an $\mathrm{X}$ in the box.

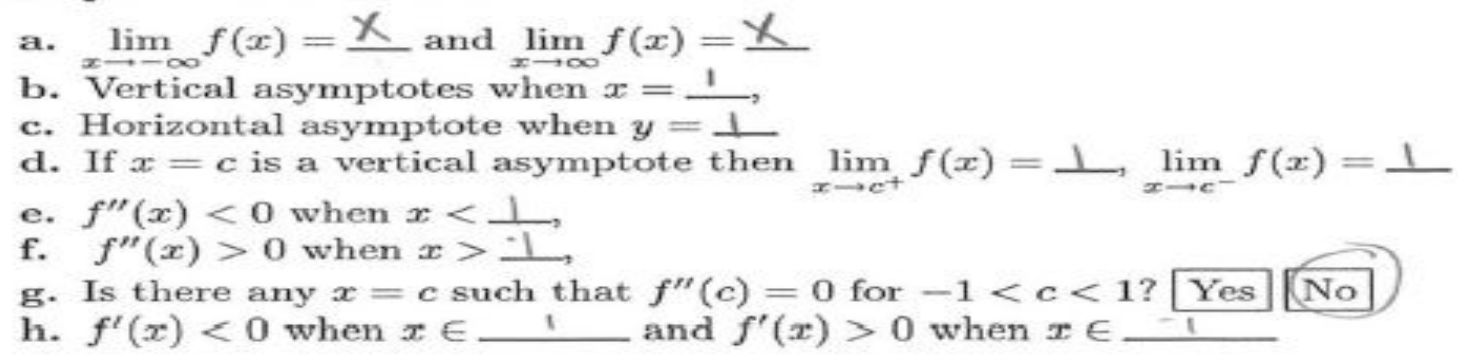

Figure 3. Response of Participant 1 who classified to be in the Action stage of APOS.

Participant 2, who classified to be in the Object category, changed some of the responses (displayed in Figure 4 below) during the oral interview and corrected some parts while having hard time to respond part (h) of the question. 


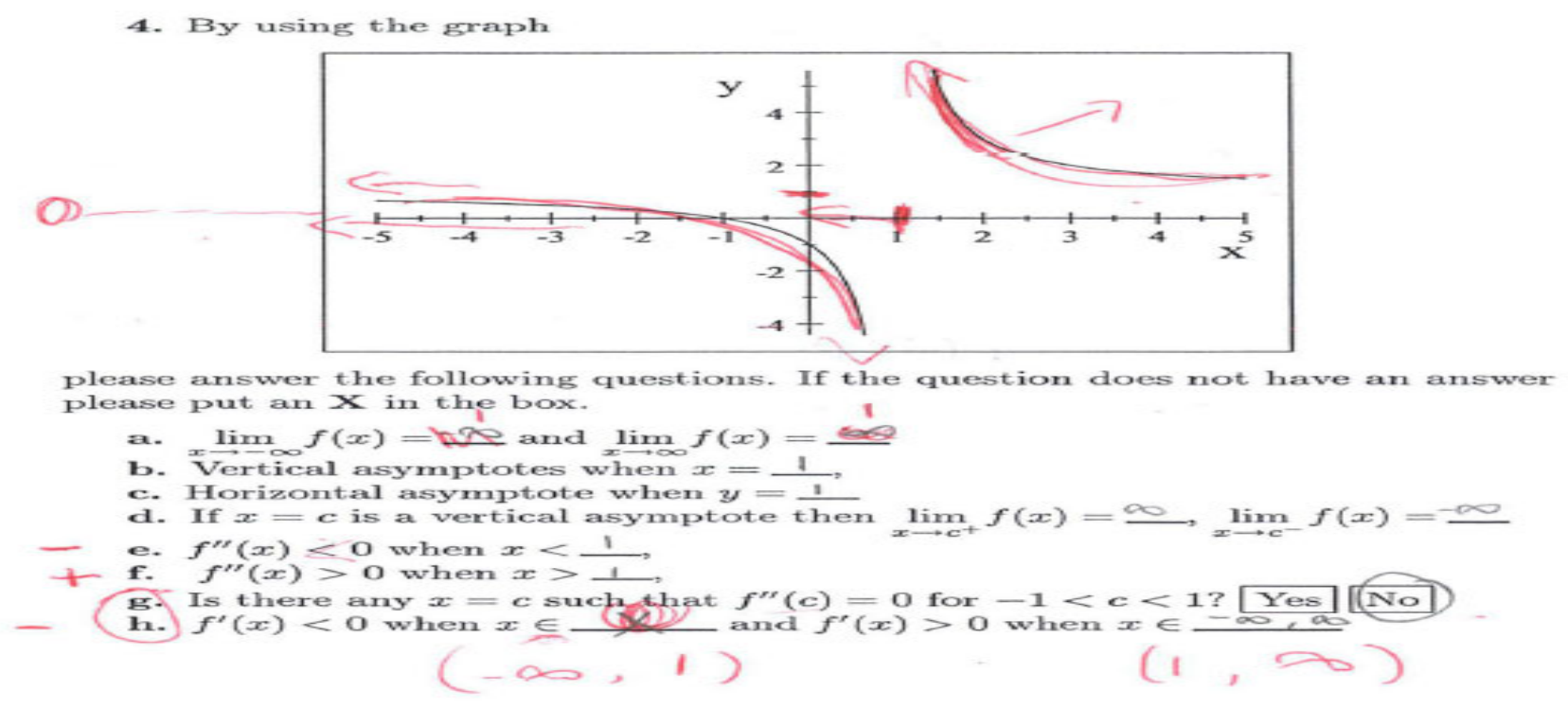

Figure 4. Response of Participant 2 classified to be in the Object stage of APOS.

Participant 4 had a well-established conceptual understanding that was displayed during the oral interview. The response (shown in Figure 5) of this participant during the written portion of data collection was close enough to the expected correct answer.

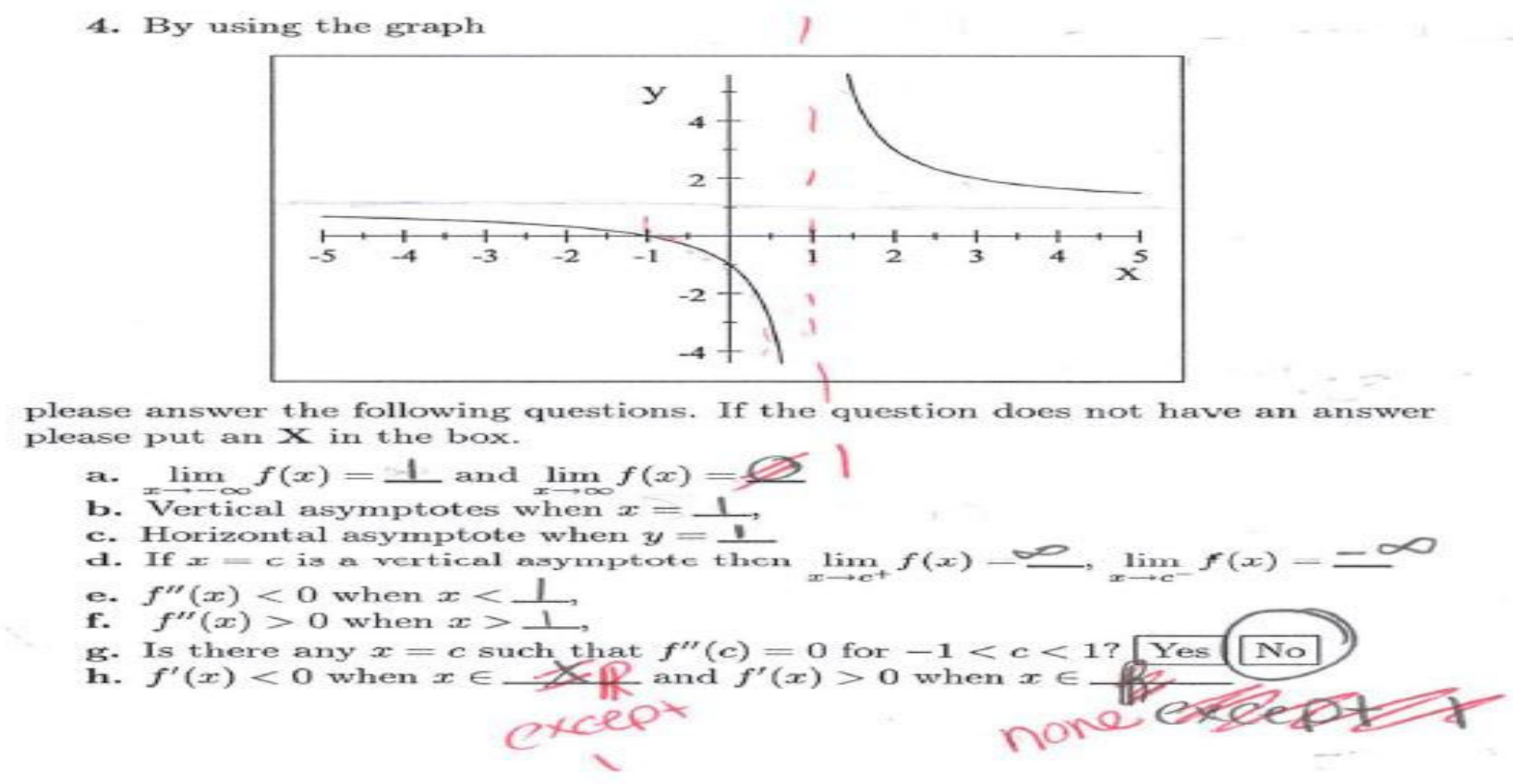

Figure 5. Response of Participant 4 who classified to be in the Schema stage of APOS.

Participant 10 is classified to be at the Process level of APOS. This participant's responses displayed in Figure 6 to parts (a)-(h) were sophisticated, however, didn't have a comprehensive approach to the solution with some of the mistakes made. 


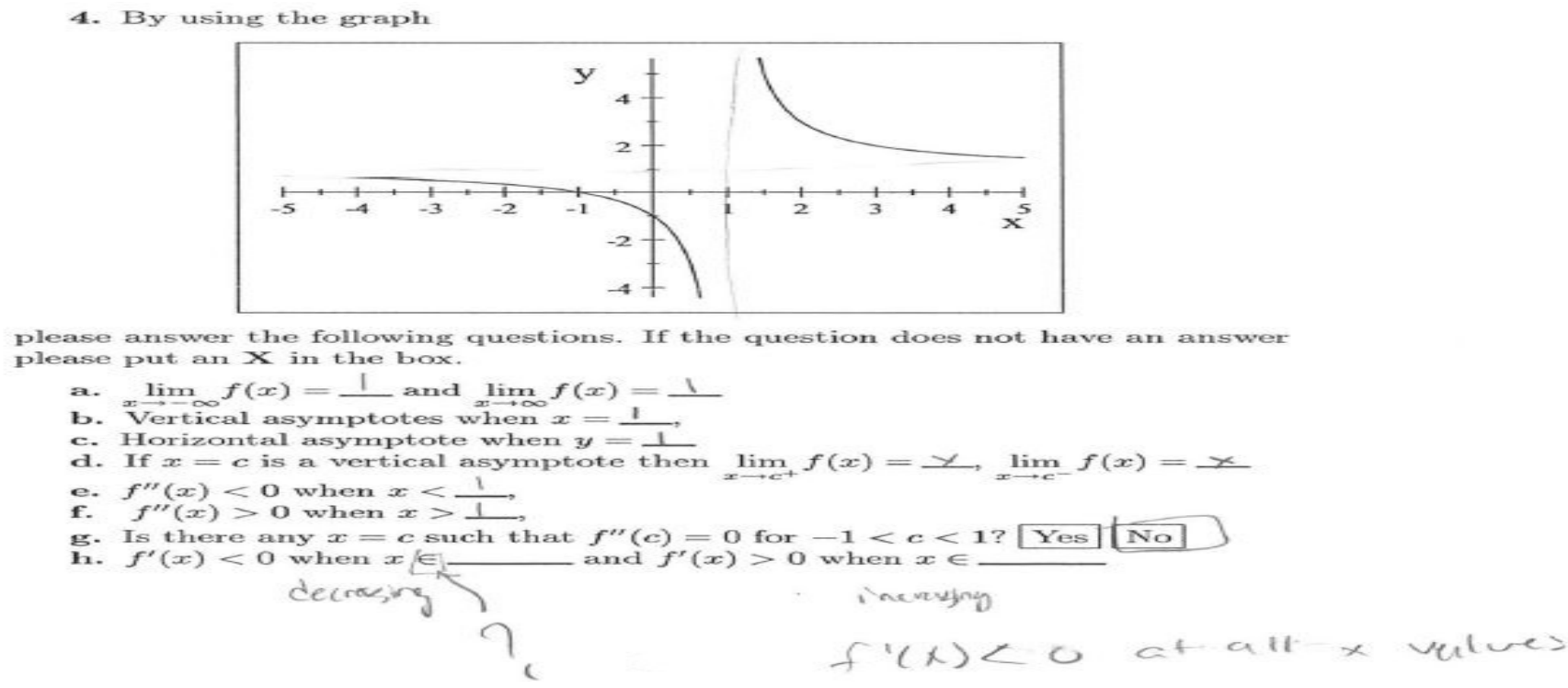

Figure 6. Response of Participant 10 who classified to be at the Process stage of APOS.

Participant 18 is classified to be in the Schema level of APOS and showed a strong knowledge of the connection between the concepts during the oral interview. This participant was able to respond to the written questionnaire correctly and explain the connection between the concepts in detail during the oral interview.

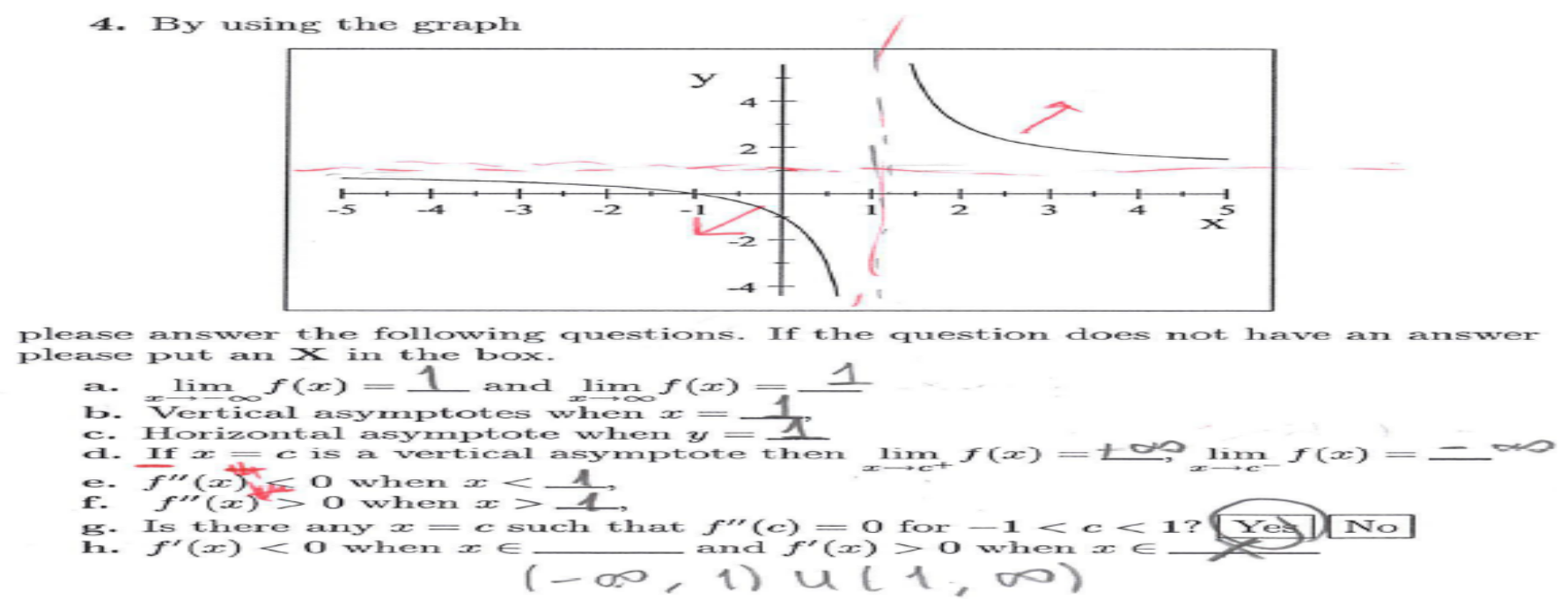

Figure 7. Response of Participant 18 who classified to be at the Schema stage of APOS.

\section{Conclusion}

In this work, the emphasis is given to understanding and measuring engineering students' ability to respond a variety of calculus questions after analyzing a graph of a function which is commonly seen in STEM applications. The responses of 19 undergraduate students to a research question are analyzed qualitatively and quantitatively. The data is collected at a mid-sized Northeastern university in the United States with the attainment of the IRB approval to conduct the research. The qualitative data analysis consisted of transcribed written questionnaire responses of the participants to the research question while APOS classification and the triangulation of the correct responses of the participants are the two quantitative analysis methods used for measurable outcomes. Table 3 and Figure 8 below summarizes the participants' classification to the research questions. 


\begin{tabular}{|l|l|l|l|l|l|l|l|l|l|}
\hline Classification & \multicolumn{5}{|c|}{ Triangulation of the correct responses } & \multicolumn{3}{c|}{ APOS classification } \\
\hline Sub-classification & Fifth & Fourth & Third & Second & First & Action & Process & Object & Schema \\
\hline Participant (RP) & 9,17 & $\begin{array}{l}1,5,11, \\
14,15\end{array}$ & $\begin{array}{l}3,8,10, \\
13,16\end{array}$ & $2,6,7,12$ & $4,18,19$ & $\begin{array}{l}1,5,7,9,11, \\
14-18\end{array}$ & $3,10,13$ & $2,6,12$ & $4,18,19$ \\
\hline Percentage (\%) & 10.52 & 26.32 & 26.32 & 21.05 & 15.79 & 52.63 & 15.79 & 15.79 & 15.79 \\
\hline
\end{tabular}

Table 3. Summary of the APOS classification and Triangulation of the correct participant responses.

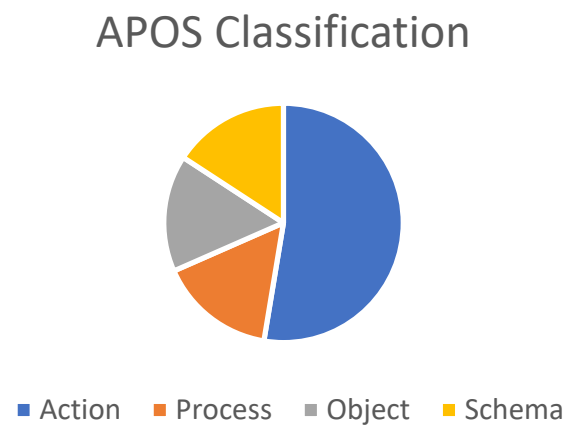

Correct Response Triangulation

Figure 8. APOS classification and Triangulation of participants.

The following APOS classification is applied for attaining the results in Table 3 above.

- Action: The participants were able to transform the given information to the graph by performing the required operations to achieve the expected solution for limits, derivative or asymptote to an extent. The participants in this group respond to the research questions during the pre- or post-interview period based on each sub-calculus concept.

- Process: The individual reflects upon the action when the action is repeated and he or she can make an internal mental construction called a process by which the individual can think of as performing the same kind of action without an external support. The participants classified in this group were able to answer the research question without any guidance from the researcher per sub-calculus concept covered in the question.

- Object: The individual is aware of the connectedness of the calculus sub-concepts that take place in the question (i.e. derivative, limit and asymptote) and uses this totality by transforming it to answer the questions correctly...

- Schema: The participant links actions, processes, objects, and other schemas that help to form a framework by using general principles in mind. In other words, the participant can make informed judgement of each step of the calculus sub-concepts that take place on the graph and connects these sub-concepts to be able to answer the question correct.

In this work we introduced the Triangulation method to categorize participants' correct responses. This method's results displayed in Figure 2 contains a triangular coverage of the correct responses of the participants. $86.32 \%$ of the correct responses (101/117) fall within the large triangle displayed on the figure; even though the triangle does not contain all the highlighted correct responses, it is a strong indicator of the success of the students in a specific order. This method can be used by educators to evaluate questions of similar questions' numerical evaluation. 
The comparison of the results in Table 3 can clearly indicate the difference between the APOS theory application and the triangulation of the correct responses of the participants. Even though there is an overlap in each group of participants, APOS theory analyzes the responses from conceptual building blocks of knowledge while triangulation of responses directly relies on the responses to the concepts. The triangulation of the respondents' correct responses appears to be much easier to apply for numerical evaluation when compared to the APOS theory classification for quantitative classification. We invite other researchers to apply the techniques that we used and introduced in this work to other empirical data sets for attaining measurable outcomes.

\section{References}

[1] Asiala, M., Brown, A., DeVries, D. J., Dubinsky, E., Mathews, D., \& Thomas K. (1997). A framework for research and curriculum development in undergraduate mathematics education. In J. Kaput, A. H. Schoenfeld, \& E. Dubinsky (Eds.), Research in collegiate mathematics education II (p/. 1-32). Providence, RI: American Mathematical Society and Washington, DC: Mathematical Association of America.

[2] Baker, B., Cooley, L., \& Trigueros, M. (2000). A calculus graphing schema, Journal for Research in Mathematics Education, 31(5), 557-578.

[3] Breidenbach, D., Dubinsky, E., Hawks, J., \& Nichols, D. (1992). Development of the process of function, Educational Studies in Mathematics, 23(3), 247-285.

[4] Clark, J. M., Cordero, F., Cottrill, J., Czarnocha, B., DeVries, D. J., St. John, D., Tolias, G., \& Vidakovic, D. (1997). Constructing a schema: The case of the chain rule? Journal of Mathematical Behavior, 16(4), 345-364.

[5] Cooley, L., Trigueros M., \& Baker B. (2007). Schema thematization: A theoretical framework and an example. Journal for Research in Mathematics Education, 38(4), 370 - 392.

[6] Dubinsky, E. \& McDonald M. A. (2002). APOS: A Constructivist Theory of Learning in Undergraduate Mathematics Education Research, The Teaching and Learning of Mathematics at University Level, 7 (3), 275-282.

[7] Piaget, J. (1971). Psychology and epistemology (A. Rosin, Trans.). London: Routledge and Kegan Paul. (Original Work Published 1970.)

[8] Piaget, J., J.-B.Grize, A., Szeminska, \& V.Bang (1977). Epistemology and psychology of functions (J. Castellano's and V. Anderson: Trans.)

[9] Tokgoz, E., \& Ceyhan, H. (2017, June), Integral Concept and Decision Making: Do the STEM Majors Know When to Use Numerical Methods for Integral Approximation? Paper presented at 2017 ASEE Annual Conference \& Exposition, Columbus, Ohio. https://peer.asee.org/28543. 